\title{
No Associations Found between PGBD1 and the Age of Onset in Japanese Patients Diagnosed with Sporadic Alzheimer's Disease
}

\author{
Tohru Ohnuma Tohru Nakamura Yuto Takebayashi \\ Ryo Hanzawa Maiko Kitazawa Ryoko Higashiyama \\ Mayu Takeda Katrin Thompson Miwa Komatsu \\ Hiromi Shimazaki Nobuto Shibata Heii Arai \\ Department of Psychiatry, Juntendo University School of Medicine, Tokyo, Japan
}

\section{Key Words}

PGBD1 - Alzheimer's disease · Polymorphism • Age of onset

\begin{abstract}
Background/Aims: PiggyBac transposable element derived 1 (PGBD1) encodes a molecule involved in epigenetic mechanisms that have been implicated in Alzheimer's disease (AD), and recent genome-wide association studies and meta-analyses have indicated that a single nucleotide polymorphism (SNP), rs3800324, in PGBD1 could be associated with AD and the age of onset. However, no Japanese patients were examined in these studies. The aim of the present study was to replicate the previous finding in Japanese AD cases. Methods: We performed a case-control study (211 cases and 156 controls) to investigate the association between PGBD1 and Japanese AD using 4 tag SNPs including rs3800324. Results: Single SNP and haplotype analysis showed no association between $A D$ and age of onset, whereas genotypic and allelic frequencies of the $\varepsilon 4$ of apolipoprotein $E(A P O E)$ showed an association with $A D$ as expected. Conclusion: In Japanese $A D$, we observed no influence of $P G B D 1$, as either a risk factor or a modifier, even though $A P O E$ was associated with $A D$ in this population.
\end{abstract}




\section{Introduction}

Several studies have investigated the etiology of Alzheimer's disease (AD) and conducted genetic analyses to identify specific candidate genes. Mutations in amyloid- $\beta$ precursor protein (A $\beta P P)$, presenilin-1 (PS1), and presenilin-2 (PS2) genes are well-known genetic causes for familial AD [1]. However, for sporadic and late-onset AD, although the $\varepsilon 4$ of apolipoprotein $\mathrm{E}(A P O E)$ is a robust genetic risk factor for $\mathrm{AD}$ [2] with a gene-dose effect [3] and a relationship with the age of onset $[3,4]$, it cannot explain all aspects of the onset of $\mathrm{AD}$ [3]. Indeed, parallel to findings from genetic studies, environmental factors have also been implicated to play an integral role in $\mathrm{AD}$. In addition to genetic candidates, environmental factors have also arisen as risk factors for AD, including diabetes mellitus [5], smoking [6], hypertension [7, 8], and low levels of nutritional antioxidants (e.g., vitamin C and E) [9]. Previously, epidemiological factors such as epigenetic mechanisms have also been suggested to play a role in AD $[10,11]$. Epigenetics has been implicated in several complex diseases. Hypotheses involving epigenetic mechanisms, which do not involve alterations in the DNA sequence, have been suggested regarding changes in gene expression and protein activity or as additive factors for the genetic risk in AD patients. Previously, a relationship between DNA methylation, one type of epigenetic mechanisms, and AD was reported [12]. DNA methylation is also involved in retroposons, another type of epigenetic mechanisms $[13,14]$. PiggyBac transposable element derived 1 (PGBD1) is a member of one of the families of transposases related to transposons, and belongs to the subfamily of PGBD genes. This gene product is specifically expressed in the brain, but its exact function is still unknown. A genome-wide association study of family-based case-control studies suggested that $P G B D 1$ is involved in $\mathrm{AD}[15,16]$. In addition, although weak (the minor allele was associated with an age of onset 1 year earlier than the major allele), a single nucleotide polymorphism (SNP) in PGBD1, rs3800324, has been shown to be associated with the age of onset in $\mathrm{AD}$, as a risk modifier in a meta-analysis study [17]. However, no Japanese AD patients were examined in any of these studies. Thus, PGBD1 may be related to an important aspect of the pathophysiology of $\mathrm{AD}$ involving an epigenetic mechanism, especially retroposons.

In the present study, we performed a case-control study to investigate whether PGBD1 is associated with $\mathrm{AD}$ using Japanese common tag SNPs, and also if PGBD1 could modulate the age of $\mathrm{AD}$ onset considering the $A P O E$ genotype status.

\section{Patients and Methods}

Our samples from sporadic Japanese AD patients $(n=211$, male:female $=98: 113)$ were obtained from the Department of Psychiatry, Juntendo University Hospital, Tokyo, Japan, and the Department of Psychiatry, Juntendo Koshigaya Hospital, Saitama, Japan. The control samples $(n=156$, male:female $=74: 82)$ were obtained from healthy volunteers from our hospital staff who had no history of dementia or other neuropsychiatric diseases. All AD cases were diagnosed according to the NINCDS-ADRDA criteria [18], and none had a familial history of AD. The mean age $( \pm S D)$ of the AD group $(68.1 \pm 10.8$ years) was not significantly different from that of the control group (62.1 \pm 8.1 years) with the Student $t$ test $(t=5.87, p>0.05)$. Additionally, the distribution of males and females within the two groups was not significantly different $\left(\chi^{2}=0.05, \mathrm{p}>0.05\right)$. The previous study reported that the minor allele of rs3800324 in PGBD1 is associated with an age of onset only 1 year earlier than the major allele [17]. Therefore, to accurately investigate the relationship between the age of onset and $P G B D 1$, only the apparent age of onset (accurate within less than 1 year)

\section{(1)}


obtained from information from the patients' families (age when any criteria of NINCDSADRDA had appeared) from 67 present AD cases (60.5 \pm 10.1 years; range 44-81) was used for analysis. An accurate age of onset, with an error less than 1 year, was not obtained from the remaining 144 patients, and these were excluded from the analysis regarding the age of onset.

Written informed consent was obtained from all participants after the procedures had been fully explained in detail to each patient and his/her family. The present study was carried out in compliance with the World Medical Association's Declaration of Helsinki and was approved by the Ethics Committee of the Juntendo University School of Medicine.

Genomic DNA was extracted from peripheral white blood cells using a QIAamp ${ }^{\circledR}$ DNA Blood Maxi kit (Qiagen, Courtaboeuf, France). For the selection of SNPs, tag SNPs for PGBD1 $\left[r^{2}>0.8\right.$, minor allele frequencies $\left.(\mathrm{MAF})>0.05\right]$ were chosen from the International HapMap Project database (release 27, Phase II + III, February 2009, on NCBI B36 assembly, dbSNP b126) using the TAGGER algorithm with a successful TaqMan probe design. Additionally, a reported missense SNP, rs3800324 (G>A, Gly244Glu) showing a MAF >0.05 within a Japanese population, was also chosen as a candidate SNP for PGBD1 from the dbSNP database (http:/www.ncbi.nlm.nih.gov/SNP/). Thus, the following 4 SNPs were investigated for PGBD1: rs2142731, rs3800324, rs3800327, and rs2142730 (the 'rs' notation in front of each SNP represents the identification from the US National Center for Biotechnology Information SNP cluster within the dbSNP database; http:/www.ncbi.nlm.nih.gov/SNP/). All of these SNPs were analyzed using TaqMan ${ }^{\circledR}$ technology (Assay-by-Design ${ }^{\mathrm{TM}}$ ). Excluding the missense SNP rs3800324, all other SNPs were intronic tag SNPs (genomic map and structures of the human PGBD1 gene, including the location of the SNPs, were shown in our previous study [19]). All investigated SNPs were typed using TaqMan technology with an ABI7500 system (Applied Biosystems, Foster City, Calif., USA). All probes and primers were designed by the Assay-by-Design service for Applied Biosystems. Polymerase chain reaction (PCR) was done with the standard PCR MasterMix reagent kit using a 4- $\mu$ l volume. Additionally, to ensure the quality of the results, we confirmed the SNPs from a few randomly chosen individuals using a direct DNA sequencing method to check for errors in the TaqMan method. All genotypes determined by direct sequencing were in agreement with the genotypes obtained by the TaqMan method for all investigated SNPs. Detailed information on PCR conditions and primer pairs is available upon request. APOE genotypes for all samples were determined according to a previous report [20].

Differences in age between healthy controls and patients were examined using twotailed Student's t test, and the $\chi^{2}$ test was used to examine differences in gender distribution. For the case-control association study, Hardy-Weinberg equilibrium (HWE) testing of the SNPs was done using SNPAlyze V7.0 Pro (Dynacom, Chiba, Japan). The HWE tests were carried out for all loci in patients and controls. Differences in genotypic and allelic frequencies were evaluated based on the case-control design using $\chi^{2}$ analysis. Linkage disequilibrium (LD), denoted as $D^{\prime}$, was calculated from the haplotype frequency using the expectation-maximization algorithm. The LD block was also identified using SNPAlyse software when $D^{\prime}$ was greater than 0.75 . Case-control haplotype analysis was also performed using SNPAlyse software. Permutation analysis was used to determine the empirical significance and to calculate the $\mathrm{p}$ values based on 10,000 replications. The global $\mathrm{p}$ values represent the overall significance using the $\chi^{2}$ test when the observed versus expected frequencies of all haplotypes are considered together. Individual haplotypes were tested for association by grouping all other haplotypes together and applying the $\chi^{2}$ test with 1 d.f. All $p$ values reported are two-tailed. Statistical significance was defined at $\mathrm{p}<0.05$. 
Patients Diagnosed with Sporadic Alzheimer's Disease

We performed power calculations using the Power Calculator (http://www.sph.umich. edu/csg/abecasis/CaTS/). Power was calculated under the prevalence of 0.05 using an additive or a multiplicative model, based on allelic frequencies of the associated markers ranging from 0.22 (rs2142731) to 0.44 (rs3800327), with odds ratios (ORs) ranging from 1.057 (rs2142731) to 1.305 (rs2142730) for the SNPs investigated and an alpha level of 0.05 .

To analyze interactions between SNPs in PGBD1 and APOE genotypes, logistic regression analysis was performed using HealthSketch version 2.5 (Dynacom). The probability $\left(\mathrm{P}_{\mathrm{c}}\right)$ of an individual being a case rather than a control is assumed to be affected by a set of SNPs, according to the logistic model. For example, $\operatorname{logit}(\mathrm{P})=b_{0}+b_{1} x_{1}+b_{2} x_{2}$ for a single SNP. Here, we use a coding scheme $x_{1}=-1,0,1$ and $x_{2}=-0.5,0.5,-0.5$ for genotypes homozygous for major alleles, heterozygous, and homozygous for minor alleles (for APOE, $\varepsilon 4$ was assumed to be the minor allele, and $\varepsilon 2$ and $\varepsilon 3$ were assumed to be major alleles simultaneously), respectively, to represent an additive effect with $x_{1}$ and a dominant/recessive effect with $x_{2}$. The weights were estimated with the maximum likelihood method and tested by comparison with the null hypothesis $\operatorname{logit}\left(\mathrm{P}_{\mathrm{c}}\right)=b_{0}$ (constant). We performed a stepwise forward selection procedure with two purposes: the first was to test the relationships among multiple SNPs in $P G B D 1$ and the $A P O E$ genotype, and the second was to confirm the interaction among the SNPs if a significant association with $\mathrm{p}<0.05$ was shown with individual logistic models. Multiple regression analyses were performed to estimate the relationship among the age of onset, APOE status, and the 4 SNPs using SPSS software ver. 17.0 for Windows (IBM, Chicago, Ill., USA).

\section{Results}

Ultimately, 4 SNPs in PGBD1 were genotyped, and the APOE genotype status was obtained in 211 patients with $\mathrm{AD}$ and 156 controls, with a genotyping completeness that ranged from 99.5 to $99.9 \%$. Results for power analyses demonstrated that the power ranged from $14 \%$ (rs3800324) to 84\% (rs2142730). No deviations from HWE in either patient or control samples were observed (all p >0.05; table 1).

No SNPs in PGBD1 showed any significant association between their allelic or genotypic frequencies and $\mathrm{AD}$ (table 1). $D^{\prime}>0.75$ was assumed to represent a strong $\mathrm{LD}$, and results indicated that all investigated SNPs for each gene displayed a strong LD block in controls and patients with AD (all $D^{\prime}>0.95$ ) as we previously reported in Japanese controls [19]. Additionally, case-control haplotype association analyses using windows of 2, 3, or 4 SNPs were performed (minor haplotypes with frequencies less than $3 \%$ in both the $\mathrm{AD}$ cases and controls were omitted), and no haplotype analysis showed a significant association with AD (table 1). As expected, genotypic and allelic frequencies of APOE showed a significant association with $\mathrm{AD}$, with an increased frequency of $\varepsilon 4$ in $\mathrm{AD}$ (table 1 ).

We further evaluated the relationships and interactions among the 4 SNPs in PGBD1 and the $A P O E$ genotype using logistic regression analysis, which can test for a combinatorial effect of multiple SNPs and confirm interactions among the 4 SNPs in PGBD1 and the APOE genotype with a stepwise procedure. We did not identify any significant interactions between any combinations of SNPs. Again, only the additive and dominant/recessive models for $A P O E$ showed a significant association with the onset of $\mathrm{AD}$ (OR 2.11 and 1.96, respectively, all $\mathrm{p}<0.01$ based on the Wald test).

Multiple regression analyses did not show any relationship among the age of onset, $A P O E$ status, and/or the 4 SNPs in PGBD1 (all $\mathrm{p}>0.05$ ). 
Patients Diagnosed with Sporadic Alzheimer's Disease

Table 1. Distribution and statistical analysis of the PGBD1 polymorphisms and their 2, 3, and 4 SNP-based haplotype analyses with $A P O E$ genotype distribution

a PGBD1 polymorphisms and their 2, 3, and 4 SNP-based haplotype analyses

\begin{tabular}{|c|c|c|c|c|c|c|c|c|c|c|c|c|c|}
\hline & \multicolumn{3}{|c|}{ Genotype frequency, n (\%) } & \multirow[t]{2}{*}{$\begin{array}{l}\mathrm{p} \\
\text { value }\end{array}$} & \multirow{2}{*}{$\begin{array}{l}\text { HWE } \\
\mathrm{C}^{*} / \mathrm{AD}^{* *}\end{array}$} & \multicolumn{2}{|c|}{$\begin{array}{l}\text { Allele frequency } \\
\mathrm{n}(\%)\end{array}$} & \multirow[t]{2}{*}{$\chi^{2}$} & \multirow[t]{2}{*}{$\begin{array}{l}\mathrm{p} \\
\text { value }\end{array}$} & \multirow{2}{*}{$\begin{array}{l}\text { OR } \\
(95 \% \mathrm{CI})\end{array}$} & \multicolumn{3}{|c|}{$\begin{array}{l}\text { Haplotype analysis } \\
\text { (global p value) }\end{array}$} \\
\hline & & & & & & & & & & & $\begin{array}{l}2 \text { SNP- } \\
\text { based }\end{array}$ & $\begin{array}{l}3 \text { SNP- } \\
\text { based }\end{array}$ & $\begin{array}{l}4 \text { SNP- } \\
\text { based }\end{array}$ \\
\hline rs2142731 & $\mathrm{A} / \mathrm{A}$ & $\mathrm{A} / \mathrm{G}$ & $\mathrm{G} / \mathrm{G}$ & \multirow{3}{*}{0.858} & \multirow{3}{*}{$0.472 / 0.831$} & $\mathrm{~A}$ & G & \multirow{3}{*}{0.095} & \multirow{3}{*}{0.758} & \multirow{3}{*}{$\begin{array}{l}1.057 \\
(0.788-1.502)\end{array}$} & & & \\
\hline $\mathrm{AD}$ & $128(60.7)$ & $74(35.1)$ & $9(4.3)$ & & & $330(78.2)$ & $92(21.8)$ & & & & & & \\
\hline $\mathrm{C}$ & $91(58.3)$ & $59(37.8)$ & $6(3.8)$ & & & $241(77.2)$ & $71(22.7)$ & & & & 0.718 & & \\
\hline rs3800324 & $\mathrm{G} / \mathrm{G}$ & $\mathrm{G} / \mathrm{A}$ & $\mathrm{A} / \mathrm{A}$ & \multirow{3}{*}{0.930} & \multirow{3}{*}{$0.857 / 0.900$} & G & $\mathrm{A}$ & \multirow{3}{*}{0.146} & \multirow{3}{*}{0.703} & \multirow{3}{*}{$\begin{array}{l}1.062 \\
(0.779-1.448)\end{array}$} & & & \\
\hline $\mathrm{AD}$ & $91(43.1)$ & $95(45.0)$ & $25(11.8)$ & & & 277 (65.6) & $145(34.4)$ & & & & & 0.525 & \\
\hline $\mathrm{C}$ & $70(44.9)$ & $69(44.2)$ & $17(10.9)$ & & & $209(67.0)$ & $103(33.0)$ & & & & 0.852 & & 0.343 \\
\hline rs3800327 & $\mathrm{G} / \mathrm{G}$ & $\mathrm{G} / \mathrm{C}$ & $\mathrm{C} / \mathrm{C}$ & \multirow{3}{*}{0.781} & \multirow{3}{*}{$0.602 / 0.330$} & G & $\mathrm{C}$ & & & \multirow{3}{*}{$\begin{array}{l}1.103 \\
(0.821-1.483)\end{array}$} & & & \\
\hline $\mathrm{AD}$ & $62(29.4)$ & $112(53.1)$ & $37(17.5)$ & & & $236(55.9)$ & $186(44.1)$ & 0.425 & 0.515 & & & 0.405 & \\
\hline C & $51(32.7)$ & $80(51.3)$ & $25(16.0)$ & & & $182(58.3)$ & $130(41.7)$ & & & & 0.210 & & \\
\hline $\mathrm{AD}$ & $102(48.3)$ & $95(45.0)$ & $14(6.6)$ & \multirow[t]{2}{*}{0.118} & \multirow[t]{2}{*}{$0.871 / 0.254$} & 299 (70.9) & $123(29.1)$ & 2.781 & 0.095 & \multirow{2}{*}{$\begin{array}{l}1.305 \\
(0.954-1.786)\end{array}$} & & & \\
\hline $\mathrm{C}$ & $67(42.9)$ & $69(44.2)$ & $20(12.8)$ & & & $203(65.1)$ & 109 (34.9) & & & & & & \\
\hline
\end{tabular}

b $A P O E$ genotype distribution

\begin{tabular}{|c|c|c|c|c|c|c|c|c|c|c|c|c|c|}
\hline & \multicolumn{6}{|c|}{ Genotype frequency, n (\%) } & \multirow[t]{2}{*}{$\mathrm{p}$ value } & \multicolumn{3}{|c|}{ Allele frequency, n (\%) } & \multirow[t]{2}{*}{$x^{2}$} & \multirow{2}{*}{$\begin{array}{l}\mathrm{OR}^{1} \\
(95 \% \mathrm{CI})\end{array}$} & \multirow[t]{2}{*}{$\mathrm{p}$ value } \\
\hline & $\varepsilon 2 / \varepsilon 2$ & $\varepsilon 2 / \varepsilon 3$ & $\varepsilon 2 / \varepsilon 4$ & $\varepsilon 3 / \varepsilon 3$ & $\varepsilon 3 / \varepsilon 4$ & $\varepsilon 4 / \varepsilon 4$ & & $\varepsilon 2$ & $\varepsilon 3$ & $\varepsilon 4$ & & & \\
\hline $\mathrm{AD}$ & $1(0.5)$ & $4(1.9)$ & $3(1.4)$ & $117(55.5)$ & $66(31.3)$ & $20(9.5)$ & \multirow[b]{2}{*}{0.0017} & $9(2.1)$ & $304(72.0)$ & $109(25.8)$ & \multirow[t]{2}{*}{17.4} & 2.177 & \multirow[b]{2}{*}{0.0001} \\
\hline $\mathrm{C}$ & $4(2.6)$ & $5(3.2)$ & $0(0)$ & $106(67.9)$ & $39(25.0)$ & $2(1.3)$ & & $13(4.2)$ & $256(82.1)$ & $43(13.8)$ & & $(1.477-3.215)$ & \\
\hline
\end{tabular}

\section{Discussion}

In the present study, $P G B D 1$, a member of one of the families of transposases that may be involved in $\mathrm{AD}[15,16]$, was investigated for an association with Japanese AD. No single SNP and/or haplotype in our case-control analysis of PGBD1 showed an association with Japanese AD. In addition, although a missense SNP, rs3800324 in PGBD1, showed an association with the age of onset in AD as reported previously [17], the association of the same SNP in the present group of Japanese participants was not replicated. That previous study was performed with a sufficiently large number of cases (2,455 Caucasian cases) [17]. We are aware that the main limitation of our present study is the small number of participants, and we should carefully interpret the present negative findings. Our results may have involved a type II error (false negative) because although the influence of the $\varepsilon 4$ allele in $A P O E$ in the present study showed statistical significance, the OR for the $\varepsilon 4$ allele in the present AD cases (OR 2.177, 95\% C 1.477-3.215) was lower than that observed in a previous study (OR 3.2, 95\% CI 2.9-3.5) [21]. This was probably due to the small number of cases. However, although the $\varepsilon 4$ genotypic and allelic frequencies were lower than expected, we observed a reproducible association in the present Japanese AD cases. Thus, we conclude that PGDB1 did not affect the age of onset per se in Japanese AD patients to the same degree as the genetic influence of APOE. On the other hand, ethnic differences (Caucasian and Japanese) and differences in 
the subtype of $\mathrm{AD}$ [late-onset $\mathrm{AD}$ in the previous study (mean age approx. 78 years) [17] and both early- and late-onset $\mathrm{AD}$ in the present study (mean age \pm SD $60.5 \pm 10.1$ years, range 44-81, for the 67 cases with the known age of onset)] may also have led to the different results.

Here, we report our current data that will be used for a future meta-analysis study in Japanese $\mathrm{AD}$ patients and conclude that the influence of $P G B D 1$ as genetic risk factor in disease onset and for the age of onset as a modifier factor is not present in Japanese sporadic $\mathrm{AD}$.

\section{Acknowledgements}

Funding for this study was provided by the Juntendo Institute of Mental Health in 2012.

\section{Disclosure Statement}

We have no potential conflicts of interest.

\section{References}

1 Bettens K, Sleegers K, Van Broeckhoven C: Current status on Alzheimer disease molecular genetics: from past, to present, to future. Hum Mol Genet 2010;19:R4-R11.

-2 Strittmatter WJ, Saunders AM, Schmechel D, Pericak-Vance M, Enghild J, Salvesen GS, Roses AD: Apolipoprotein E: high-avidity binding to beta-amyloid and increased frequency of type 4 allele in late-onset familial Alzheimer disease. Proc Natl Acad Sci USA 1993;90:1977-1981.

-3 Corder EH, Saunders AM, Strittmatter WJ, Schmechel DE, Gaskell PC, Small GW, Roses AD, Haines JL, Pericak-Vance MA: Gene dose of apolipoprotein E type 4 allele and the risk of Alzheimer's disease in late onset families. Science 1993;261:921-923.

-4 Okuizumi K, Onodera O, Tanaka H, Kobayashi H, Tsuji S, Takahashi H, Oyanagi K, Seki K, Tanaka M, Naruse S, et al: ApoE-epsilon 4 and early-onset Alzheimer's. Nat Genet 1994;7:10-11.

-5 Biessels GJ, Staekenborg S, Brunner E, Brayne C, Scheltens P: Risk of dementia in diabetes mellitus: a systematic review. Lancet Neurol 2006;5:64-74.

-6 Anstey KJ, von Sanden C, Salim A, O'Kearney R: Smoking as a risk factor for dementia and cognitive decline: a meta-analysis of prospective studies. Am J Epidemiol 2007;166:367-378.

-7 Goldstein FC, Ashley AV, Endeshaw YW, Hanfelt J, Lah JJ, Levey AI: Effects of hypertension and hypercholesterolemia on cognitive functioning in patients with alzheimer disease. Alzheimer Dis Assoc Disord 2008;22:336-342.

8 Wysocki M, Luo X, Schmeidler J, Dahlman K, Lesser GT, Grossman H, Haroutunian V, Beeri MS: Hypertension is associated with cognitive decline in elderly people at high risk for dementia. Am J Geriatr Psychiatry 2012;20:179-187.

-9 Zandi PP, Anthony JC, Khachaturian AS, Stone SV, Gustafson D, Tschanz JT, Norton MC, WelshBohmer KA, Breitner JC: Reduced risk of Alzheimer disease in users of antioxidant vitamin supplements: the Cache County Study. Arch Neurol 2004;61:82-88.

-10 Marques SC, Oliveira CR, Pereira CM, Outeiro TF: Epigenetics in neurodegeneration: a new layer of complexity. Prog Neuropsychopharmacol Biol Psychiatry 2011;35:348-355.

-11 Miller G: Epigenetics. A role for epigenetics in cognition. Science 2010;329:27.

-12 Wang SC, Oelze B, Schumacher A: Age-specific epigenetic drift in late-onset Alzheimer's disease. PLoS One 2008;3:e2698. 
13 Reuter M, Chuma S, Tanaka T, Franz T, Stark A, Pillai RS: Loss of the Mili-interacting Tudor domaincontaining protein-1 activates transposons and alters the Mili-associated small RNA profile. Nat Struct Mol Biol 2009;16:639-646.

-14 Kuramochi-Miyagawa S, Watanabe T, Gotoh K, Totoki Y, Toyoda A, Ikawa M, Asada N, Kojima K, Yamaguchi Y, Ijiri TW, Hata K, Li E, Matsuda Y, Kimura T, Okabe M, Sakaki Y, Sasaki H, Nakano T: DNA methylation of retrotransposon genes is regulated by Piwi family members MILI and MIWI2 in murine fetal testes. Genes Dev 2008;22:908-917.

-15 Bertram L, Tanzi RE: Genome-wide association studies in Alzheimer's disease. Hum Mol Genet 2009;18:R137-R145.

-16 Schjeide BM, McQueen MB, Mullin K, DiVito J, Hogan MF, Parkinson M, Hooli B, Lange C, Blacker D, Tanzi RE, Bertram L: Assessment of Alzheimer's disease case-control associations using family-based methods. Neurogenetics 2009;10:19-25.

- 17 Belbin O, Carrasquillo MM, Crump M, Culley OJ, Hunter TA, Ma L, Bisceglio G, Zou F, Allen M, Dickson DW, Graff-Radford NR, Petersen RC, Morgan K, Younkin SG: Investigation of 15 of the top candidate genes for late-onset Alzheimer's disease. Hum Genet 2011;129:273-282.

-18 McKhann G, Drachman D, Folstein M, Katzman R, Price D, Stadlan EM: Clinical diagnosis of Alzheimer's disease: report of the NINCDS-ADRDA Work Group under the auspices of Department of Health and Human Services Task Force on Alzheimer's Disease. Neurology 1984;34:939-944.

-19 Kitazawa M, Ohnuma T, Takebayashi Y, Shibata N, Baba H, Ohi K, Yasuda Y, Nakamura Y, Aleksic B, Yoshimi A, Okochi T, Ikeda M, Naitoh H, Hashimoto R, Iwata N, Ozaki N, Takeda M, Arai H: No associations found between the genes situated at 6p22.1, HIST1H2BJ, PRSS16, and PGBD1 in Japanese patients diagnosed with schizophrenia. Am J Med Genet B Neuropsychiatr Genet 2012; 159B:456-464.

20 Wenham PR, Price WH, Blandell G: Apolipoprotein E genotyping by one-stage PCR. Lancet 1991; 337:1158-1159.

-21 Hsiung GY, Sadovnick AD: Genetics and dementia: risk factors, diagnosis, and management. Alzheimers Dement 2007;3:418-427. 